\title{
Insuficiência renal: o que é, sintomas, causas e tratamento.
}

Arthur Frazão (1)

\section{CARTA AO EDITOR}

Resumo

A insuficiência renal é a incapacidade dos rins de filtrar o sangue com o objetivo de eliminar substâncias que podem ser tóxicas para o organismo quando estão em grandes concentrações no sangue, como ureia e creatinina, por exemplo. A alteração no funcionamento dos rins pode acontecer devido à desidratação, sepse ou lesão nos rins devido à presença de pedras nesses órgãos.

Palavras-chave: Insuficiência renal, Rins, Saúde renal. 


\title{
Kidney failure: what it is, symptoms, causes and treatment.
}

\begin{abstract}
Kidney failure is the inability of the kidneys to filter the blood in order to eliminate substances that can be toxic to the body when they are in high concentrations in the blood, such as urea and creatinine, for example. Changes in the functioning of the kidneys can happen due to dehydration, sepsis or damage to the kidneys due to the presence of stones in these organs.
\end{abstract}

Keywords: Kidney failure, Kidneys, Kidney health.

Instituição afiliada: 1- Médico generalista, especialista em Oftalmologia pela Universidade Federal do Rio Grande do Norte, em 2008, com registro profissional no CRM/PE 16878

Dados da publicação: Artigo recebido em 03 de junho, revisado em 25 de junho, aceito para publicação em 10 de julho e publicado em 05 de Setembro.

DOI: https://doi.org/10.36557/2674-8169.2021v3n8p26-36

(1) Carlos Arthur Frazão medfraz@gmail.com 


\section{INTRODUÇÃO}

A insuficiência renal é a incapacidade dos rins de filtrar o sangue com o objetivo de eliminar substâncias que podem ser tóxicas para o organismo quando estão em grandes concentrações no sangue, como ureia e creatinina, por exemplo. A alteração no funcionamento dos rins pode acontecer devido à desidratação, sepse ou lesão nos rins devido à presença de pedras nesses órgãos.

De forma geral, a insuficiência renal pode ser classificada em duas de acordo com a velocidade com que há perda no funcionamento do órgão e início dos sintomas:

- Insuficiência renal aguda, em que há uma rápida redução da função renal;

- Insuficiência renal crônica, em que há perda gradual da função dos rins, levando ao surgimento de sintomas progressivos.

Geralmente, a insuficiência renal aguda tem cura, porém a insuficiência renal crônica nem sempre tem cura e o tratamento normalmente é feito por meio de hemodiálise ou transplante de rim para melhorar a qualidade de vida do paciente e promover o bem-estar.

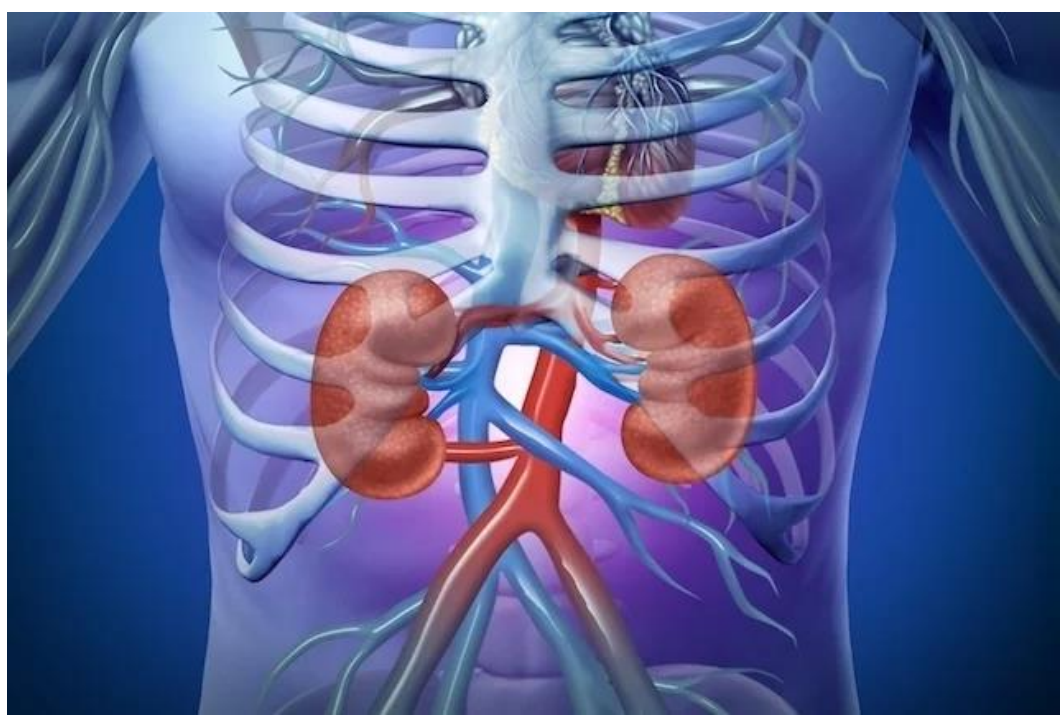

Imagem ilustrativa referente aos rins humanos. Disponível em: https://www.tuasaude.com/insuficiencia-renal/

\section{Sintomas de insuficiência renal}

Os sintomas de insuficiência renal surgem à medida que há diminuição da 
capacidade de filtração dos rins, sendo os principais:

- Pouca urina;

- Urina com cor amarela escura e com cheiro forte e espuma;

- Cansaço frequente;

- Sensação de falta de ar;

- Dor na parte inferior das costas;

- Inchaço das pernas e pés;

- Pressão alta;

- Febre superior a 39으;

- Falta de apetite;

- Náuseas e vômitos;

- Cãibras frequentes;

- Tremor, principalmente nas mãos;

- Formigamento nas mãos e nos pés;

- Pequenos caroços na pele.

Ao observar estes sintomas é aconselhado que a pessoa consulte o nefrologista ou clínico geral para que seja feita uma avaliação dos sintomas e possam ser solicitados exames que ajudem a avaliar o funcionamento do rim e, assim, ser possível iniciar o tratamento mais adequado.

O diagnóstico da insuficiência renal é feito por meio de exames de sangue, como dosagem de creatinina, ureia, sódio e potássio, e exames de urina com o objetivo de identificar a presença de proteínas na urina, o que é indicativo de alteração no funcionamento dos rins. Além disso, o médico pode indicar a realização de exames de imagem, como ultrassom, ressonância magnética ou tomografia computadorizada para a gravidade da alteração.

\section{Principais causas}

A insuficiência renal pode acontecer como consequência de algumas situações que a curto, médio ou longo prazo podem prejudicar o funcionamento dos rins, sendo as principais:

- Diminuição da quantidade de sangue no rim, devido a desidratação, mau funcionamento dos rins ou pressão baixa;

- Lesão dos rins, devido a pedras nos rins ou substâncias toxicas como medicamentos;

- Interrupção da passagem de urina, causada por aumento da próstata ou presença de 
tumor.

- Sepse, em que bactérias conseguem chegar ao rim e outras parte do corpo, podendo causar danos ao órgão;

- Doença policística renal, que é caracterizada pela presença de vários cistos no rim, podendo prejudicar o seu funcionamento;

- Uso de medicamentos e suplementos proteicos em excesso, pois podem causar danos ao órgão ou interferir em uma de suas funções;

- Síndrome hemolítico-urêmica, que é uma doença causada por uma toxina produzida por algumas bactérias e que resulta em lesão dos vasos sanguíneos, anemia hemolítica e perda progressiva da função renal.

As pessoas que possuem maiores chances de desenvolver insuficiência renal são aquelas que são diabéticas ou hipertensas e que não seguem o tratamento adequado indicado pelo médico. Além disso, antecedentes familiares de problemas renais ou pessoas que já passaram por algum transplante antes ou possuem mais de 60 anos de idade também têm mais chance de desenvolver esta doença.

\section{Como é feito o tratamento}

O tratamento para insuficiência renal deve ser orientado pelo nefrologista e pelo nutricionista, podendo ser feita em casa ou no hospital, dependendo da gravidade da doença.

Na maioria das vezes, o tratamento é feito com o uso de remédios antihipertensivos e diuréticos, pois assim é possível favorecer a eliminação de substâncias tóxicas que possam estar acumuladas no organismo.

Nos casos mais graves, principalmente na insuficiência renal crônica pode ser necessário realizar transplante de rim ou fazer hemodiálise, que é um procedimento que tem como objetivo filtrar o sangue, retirando todas as impurezas que os rins não conseguem filtrar.

Além disso, durante o tratamento para insuficiência renal, é importante que a pessoa siga uma alimentação indicada pelo nutricionista, que deve ser dieta rica em carboidratos e pobre em proteínas, sal e potássio, pois assim é possível prevenir a sobrecarga no rim. 
THE AUTHORS DECLARE NO CONFLICTS OF INTEREST.

\section{REFERÊNCIAS}

1- MINISTÉRIO DA SAÚDE. Diretrizes clínicas para o cuidado ao paciente com doença renal crônica - DCR no sistema único de saúde. 2014. Disponível em: $<$ https://bvsms.saude.gov.br/bvs/publicacoes/diretrizes_clinicas_cuidado_paciente_ren al.pdf>. Acesso em 19 Mar 2021

2- EBSERH. Insuficiência Renal Aguda. Disponível em: <http://www2.ebserh.gov.br/documents/214336/1108363/Cap\%C3\%ADtulo-37Insufici\%C3\%AAncia-Renal-Aguda.pdf/48bb79d4-7216-4da2-82b0-5259bb9db1ea>. Acesso em 19 Mar 2021

3- Tua Saúde. Disponível em: https://www.tuasaude.com/insuficiencia-renal/ 